\title{
Epenthesis and Devocalization in the Djelfa Dialect of Algerian Arabic: An OT Account
}

\author{
Khedidja Slimani \\ School of Foreign Languages, East China Normal University, China
}

Copyright $\bigcirc 2017$ by authors, all rights reserved. Authors agree that this article remains permanently open access under the terms of the Creative Commons Attribution License 4.0 International License

\begin{abstract}
The paper provides a straightforward analysis of some phonological processes attested in the Djelfa dialect, viz., epenthesis, and devocalization. The Djelfa dialect is one of the varieties of Algerian Arabic that has never been investigated before. Thus, this paper aims at delving into some of its phonological intricacies. The paper is couched within Optimality Theory framework (OT) and reveals the interaction underlying the markedness and faithfulness constraints to yield the well-formed syllable structures attested in the dialect. It mainly accounts for /i/ epenthesis to repair the undesired word-final $\mathrm{C}(\mathrm{C}) \mathrm{VVCC}$ and $\mathrm{C}(\mathrm{C}) \mathrm{VCCC}$ syllable structures, which is primarily ascribed to the interplay between $* \varsigma \varsigma$ and $* 3 \mu$. Vowel hiatus, however, is resolved by glide epenthesis unless the first member of the hiatus is [-high] and accordingly, the hegemony of CONTIGUITY-IO ([-high]V) renders devocalization imperative.
\end{abstract}

Keywords Djelfa Dialect, Epenthesis, Devocalization, Optimality Theory

\section{Introduction}

The Djelfa dialect, (DJ, henceforth) is one of the varieties of Algerian Arabic that belong to the Maghrebi Arabic Language continuum. It is spoken in the Djlefa province in north-central Algeria, located about $300 \mathrm{~km}$ south to Algiers, the capital city of Algeria. The Djelfa inhabitants belong to the Ouled Nail Tribe that has a very long history which will not be discussed here as it falls beyond the scope of this study. The current paper throws some light on devocalization and some epenthetic processes attested in DJ within the framework of OT.

Epenthesis is a recurrent theme that has been investigated in many Arabic dialects [1,2],[3], [4], [5], [6], [7], [8], [9] to name but a few. Most of the Arabic studies that revolve around epenthesis had approached the issue from three main angles: the quality of the epenthetic vowel, its docking site and stress-epenthesis interaction. But as far as I know, none of them has dealt with vowel epenthesis to break the undesired word-final $\mathrm{C}(\mathrm{C}) \mathrm{VCCC}$ and $\mathrm{C}(\mathrm{C}) \mathrm{VVCC}$ syllable structures. To fill such a gap, this paper attempts to account for /i/ epenthesis in word-final $\mathrm{C}(\mathrm{C}) \mathrm{VCCC}$ and $\mathrm{C}(\mathrm{C}) \mathrm{VVCC}$ syllables in DJ. Moreover, it addresses /i/ epenthesis in word-initial CCC clusters and devocalization in the light of OT by means of elucidating how DJ resorts to these phonotactic mechanisms to repair some banned syllable structures. The data used in the paper are collected by the author himself being a native speaker of DJ in addition to consulting some other native speakers. Thus, the paper aims at providing new data that may enrich comparative studies of Arabic dialectology.

The paper entertains Kiparsky's [6] license mora proposal. Kiparsky [6], classifies Arabic dialects in terms of the docking site of the epenthetic segment inserted to break word-medial CCC clusters into three groups: CV-dialects, VC-dialects and C-dialects. CV-dialects break the cluster as $\mathrm{CCiC}$ where the stranded $\mathrm{C}$ constitutes the onset of the epenthetic vowel.VC dialects, on the other hand, break the cluster as $\mathrm{CiCC}$ where the unsyllabified $\mathrm{C}$ forms the coda of the epenthetic vowel. $\mathrm{C}$ dialects, however, maintain the cluster intact and no epenthesis is invoked. As to the investigated dialect, we classify DJ under the $\mathrm{C}$-dialects group as word-medial CCC clusters are not interrupted by /i/ epenthesis, e.g. [ktibtha] 'I wrote it', [J uftha] 'I saw it', [ rabtha] 'I drank it'...Etc. Adopting Kiparsky's [6] model, we assume that the stranded $\mathrm{Cs}$ in DJ are licensed as semisyllables directly affiliated to the prosodic word.

The paper falls into two parts. The first part documents /i/ epenthesis in the word-final $\mathrm{CC}$ clusters that result from the concatenation of the negative morpheme / / to word-final CVVC syllables. Word-final CVVCC syllables are not tolerated in the dialect as they breach $* 3 \mu$ that is ranked very high. $* 3 \mu$ is again endangered when the negative morpheme / $/$ falls in the coda of word-final CVVC syllables which are, in turn, repaired by /i/ epenthesis. The paper also sheds light on /i/ epenthesis to resolve word-initial CCC clusters. Such clusters crop up when the passive voice marker $/ \mathrm{t} / \mathrm{is}$ prefixed to stems starting with biconsonatal clusters. Taking into consideration the untolerated word-final CVCCC and CVVCC syllables and word-initial CCCVC syllables in DJ, we assume that the core impetus motivating such an epenthetic process rests upon the dialect's ban on the adjacency of two semisyllables. The second part focuses on vowel hiatus and addresses the dialect endeavor to repair this 
anomaly via epenthesis and devocalization. At first glance, it seems that this vowel hiatus resolution is opaque. Yet, such opacity is only apparent in the way that intervocalic glide insertion is only operative when the first part of the hiatus is a high segment. We will show that the vowel hiatus resulting from the concatenation of the feminine morpheme /a/ to nouns and adjectives ending in the high vocalic segments /i/ and $/ \mathrm{u} /$ is resolved by intervocalic glide insertion, while the hiatus resulting from the concatenation of the plural morpheme $/ \mathrm{u} /$ and the imperative second singular feminine morpheme / $\mathrm{i} /$, to verbs ending in the low vowel /a/ is repaired by devocalization as the first part of the hiatus is a low vowel.

\section{Epenthesis}

\section{1. /i/ Epenthesis to Resolve Word-Final C(C)VVCC and C(C)VCCC Syllables}

When the negative morpheme $/ \int /$ is suffixed to words ending in (C)CVVC syllables, it yields phonologically ill-formed structures which are repaired by /i/ insertion as illustrated in the data in (1).

\begin{tabular}{|c|c|c|c|}
\hline Input & Output & Output & Gloss \\
\hline ma $\int$ a:f- $\int$ & *ma $\int$ a:f $\int$ & ma $\int$ a:fi $\int$ & 'he did not see' \\
\hline ma ga:l- $\int$ & *ma ga:l $\int$ & ma ga:lif & 'he did not say' \\
\hline ma da:r- $\int$ & *ma da:r $\int$ & ma da:ri & 'he did not do' \\
\hline ma kla:t- $\int$ & *ma kla:t $\int$ & ma kla:ti & 'she did not eat' \\
\hline
\end{tabular}

But when the negative morpheme $/ \int /$ is suffixed to $\mathrm{C}(\mathrm{C}) \mathrm{VV}$ or $\mathrm{CC}(\mathrm{VC}$ syllables, no epenthesis takes place. Consider the data in (2).

\begin{tabular}{|c|c|c|}
\hline Input & Output & Gloss \\
\hline ma lga: $-\int$ & ma lga: $\int$ & 'he did not find' \\
\hline ma zra:- $\int$ & ma 3ra: $\int$ & 'he did not run' \\
\hline ma fham- $\int$ & ma fham $\int$ & 'he did not understand' \\
\hline ma Sraf- $\int$ & ma Sraf $\int$ & 'he did not know' \\
\hline
\end{tabular}

As it is clearly revealed from the data in (2), when the suffix / $\int$ is concatenated to CC(VC or C(C)VV syllables, no epenthesis takes place. In Arabic CVCC and CVVC syllables are treated as superheavy syllables [2], [10], [11], [8], [6]. These syllables incur a serious cost of the foot size as they are comprised of three morae and accordingly breach $* 3 \mu$ that is undominated in Arabic.

\section{(3) $* 3 \boldsymbol{\mu}[12]$}

No trimoraic syllable.

To account for the trimoraicity of these syllables, many accounts were proposed. Hayes [13], Kager [14] Kenstowicz, [15] and Kiparsky [6] consider the final C as extrasyllabic (it falls outside the syllable domain). In this paper, we adopt Kiparsky's mora-licensing model [6] and we assume that in $\mathrm{DJ}$, the final $\mathrm{C}$ is a semisyllable directly affiliated to the prosodic word. But assigning a mora to the stranded $\mathrm{C}$ breaches LICENSE- $_{\mu}$ that is ranked very low in the dialect grammar.

\section{(4) LICENSE- $\boldsymbol{\mu}[6]$}

A mora must be affiliated with a syllable.

Now let's account for /i/ epenthesis in the data in (1). Generally speaking, epenthetic processes are syllable-conditioned i.e., they take place to repair some inputs that do not abide by the syllable structure of a given language where some stranded consonants cannot be properly syllabified [16]. Broselow [17], however, suggests that epenthesis is not necessarily syllable-conditioned as the insertion of segments sometimes takes place to break up an undesired sequence of consonants. It might be possible to attribute /i/ epenthesis in the data in (1) to the dialect's ban on $\mathrm{C}(\mathrm{C})$ VVCC syllables in word-final position. To cast this scenario in the light of OT, we may propose the markedness constraint *VVCC] $\sigma$ that bans word-final VVCC syllables. This constraint is formulated in (5).

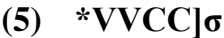

\section{No VVCC syllables.}

This banned syllable structure seems to be the main impetus for vowel epenthesis. Yet, scrutinizing abundant data form DJ reveals that $/ \mathrm{i}$ / epenthesis is again invoked to break word-final CCC clusters resultant from the concatenation of the negative morpheme $/ \int /$ to stem-final $\mathrm{CC}$ clusters. Consider the data in (6).

(6)

\begin{tabular}{|c|c|c|c|}
\hline Input & Output & Output & Gloss \\
\hline ma roht- $\int$ & $*$ ma roht $\int$ & ma rohti $\int$ & 'I did not go' \\
\hline ma biSt $-\int$ & $*$ ma biSt $\int$ & ma bif ti $\int$ & 'I did not sell' \\
\hline ma xrizt $-\int$ & $*$ ma xri3t $\int$ & ma xrizti & 'I did not go out' \\
\hline
\end{tabular}

As demonstrated in the data in (6), when the negative suffix $/ \int /$ is concatenated to CVCC syllables, it yields an unaccepted syllable structure, which again induces vowel epenthesis. To capture such banned CCC cluster by a constraint, we adopt ${ }^{*} \mathrm{CCC}$ (word-final) that can be formulated in (7).

\section{(7) * CCC(word-final)}

Tri-consonantal clusters are not allowed word-finally.

The sequence of three consonants in word-final position is banned on the grounds that it breaches *CCC (word-final) that is ranked very high in the dialect. But capitalizing on both *CCC (word-final) and *VVCC] $\sigma$ to account for $/ \mathrm{i} /$ insertion to repair the ill-formed syllable structures $\mathrm{C}(\mathrm{C})$ VVCC and $\mathrm{C}(\mathrm{C}) \mathrm{VCCC}$ resultant from the concatenation of the morpheme $/ \int /$ is deemed less economical.

Recall that the final C in CVVC and CVCC is licensed as a semisyllable in DJ. When the morpheme $/ \int /$ is appended to CVVC and CVCC syllables, one may assume that the last stranded $\mathrm{C}$ is also a semisyllable directly affiliated to the prosodic word. Yet, parsing the two stranded Cs as semisyllables is disfavored as the dialect resolves the 
undersired structure by epenthesis. It follows from this that DJ does not allow two contiguous semiyllables. To capture this scenario by a constraint, we propose the markedness constraint * $\varsigma_{\zeta}$ that should be highly ranked in the dialect grammar.

\section{(8) * $\varsigma 5$}

Two adjacent semisyllables are not allowed.

So far, we assume that the ban on two contiguous semisyllables is what motivates /i/ epenthesis in word-final $\mathrm{C}(\mathrm{C})$ VVCC and $\mathrm{C}(\mathrm{C})$ VCCC syllables. Such anomaly, however, can be resolved by shortening the nucleus of $\mathrm{C}(\mathrm{C}) \mathrm{VVCC}$ or deleting one of the last two Cs of $\mathrm{C}(\mathrm{C}) \mathrm{VCCC}$ syllables. Yet, neither of these two options is appealing as they respectively violate Max- $\mu_{\mathrm{v}}$ and MAX-IO that are ranked very high in the dialect.

\section{(9) MAX- $\mu \mathrm{v}$}

A vocalic mora in the input should be realized in the output.

\section{(10) MAX-IO [18]}

Every segment in the input should have a correspondent in the output.

As shown in the in the data in (1) and (6), DJ opts for /i/ insertion rather than segment deletion to repair the undesired $\mathrm{C}(\mathrm{C})$ VVCC and $\mathrm{C}(\mathrm{C})$ VCCC syllables. Hence, MAX-IO should outrank DEP-IO in the dialect.

\section{(11) DEP-IO [19]}

Every segment in the output should have a correspondent in the input.

The epenthetic segment /i/, however, can be either inserted before the morpheme / / by means of which the coda of the penultimate syllable syllabifies as the onset of the newly established ultimate syllable or by inserting /i/ after the morpheme $/ \int /$ where $/ \int /$ is syllabified as the onset of the newly created syllable. The second option, however, is quite hopeless as it fatally breaches $* 3 \mu$ and the correspondence constraint ANCHORING-IO $(\mathrm{GrWd}, \mathrm{R})$ that calls for the congruency between input and output in terms of the right periphery.

\section{(12) ANCHORING-IO (GrWd,R) [19]}

Any segment of the right periphery of the output GrWd has a correspondent at the right periphery of the input GrWd. (No deletion /epenthesis at the edge).

By means of defining all the relevant constraints deemed efficient to relieve the ill-formed syllable structures $\mathrm{C}(\mathrm{C})$ VVCC and $\mathrm{C}(\mathrm{C})$ VCCC, the following constraint hierarchy is adduced.

\section{(13) $* \varsigma \varsigma, * 3 \mu>>M A X-\mu v>>M A X-I O>>A N C H O R I N G-$ IO $($ GrWd,R $)>>$ DEP-IO $>>$ LICENSE- $\mu$}

Table 1 (clearly demonstrates the interaction of these constraints to optimize the optimal output [ma $\int \mathrm{a}$ :fi ] 'he did not see'.

As it turns out from the tableau above, candidate (a) is ruled out as it incurs two costs of LICENSE- ${ }_{\mu}$ and flagrantly contravenes the highly ranked markedness constraints * $\zeta \zeta$. This further confirms one of the basic tenets of DJ syllabification system that does not tolerate two adjacent semisyllables at the surface level and hence, bans $\mathrm{C}(\mathrm{C})$ VVCC and $\mathrm{C}(\mathrm{C})$ VCCC syllable structures. Candidate (b), however, is ruled out on three counts: by breaching the highly ranked constraint $* 3 \mu$, the correspondence constraint ANCHORING-IO (GrWd, R) and DEP-IO. Candidate (c) is also ousted from the competition by violating Max- $\mu_{\mathrm{v}}$ and LICENSE- $_{\mu}$. Despite the fact that candidate (d) satisfies all the three highly ranked constraints, but it is not exempted from exclusion as it incurs a blatant cost of MAX-IO. Inserting / $\mathrm{i} /$ at the right-most periphery does not secure candidate (e) as it contravenes ANCHORING-IO (GrWd, R) and DEP-IO, yet the association of the stranded $\mathrm{C}$ with a semisyllable again does not pay off and hence, leaving candidate (f) as the only potential winner by means of incurring the least violation.

Table 1. Constraint Tableau: /ma $\int$ a:f- $\int / \rightarrow$ [ma $\int$ a:fif ]

\begin{tabular}{|c|c|c|c|c|c|c|c|}
\hline $\begin{array}{l}\text { Input } \\
\text { /ma } \int \mathrm{a}: \mathrm{f}-\int /\end{array}$ & $* 55$ & $* 3 \mu$ & $M A X-\mu_{v}$ & MAX-IO & $\begin{array}{c}\text { ANCHORING-IO } \\
(\mathrm{GrWd}, \mathrm{R})\end{array}$ & DEP-IO & LICENSE $_{-\mu}$ \\
\hline a. $\operatorname{ma} \int \mathrm{a}: \mathrm{f} \mu . \int \mu$ & $* !$ & & & & & & $* *$ \\
\hline b. ma $\int$ a:f. $\int \mathrm{i}$ & & $* !$ & & & $*$ & $*$ & \\
\hline c. $\operatorname{ma} \int$ af. $\int \mu$ & & & $* !$ & & & & $*$ \\
\hline d. $\operatorname{ma} \int \mathrm{a}: \int \mu$ & & & & $*$ & & & $*$ \\
\hline e. $m a \int a: . f \mu . \int \mathrm{i}$ & & & & & $*$ & $*$ & $*$ \\
\hline f.ma $\int \mathrm{a}:$ fif & & & & & & $*$ & \\
\hline
\end{tabular}


Table 2. Constraint tableau: /ma li ab-t- $\int \rightarrow$ [ma li abti $]$

\begin{tabular}{|c|c|c|c|c|c|c|}
\hline $\begin{array}{c}\text { Input } \\
\text { /ma l?ab-t- } \int /\end{array}$ & $* 55$ & $* 3 \mu$ & MAX-IO & $\begin{array}{c}\text { ANCHORING-IO } \\
(\mathrm{GrWd}, \mathrm{R})\end{array}$ & DEP-IO & 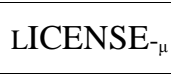 \\
\hline a. ma 12 abt $\mu . \int \mu$ & $* !$ & & & & & $* *$ \\
\hline b. ma lRabt. $\int \mathrm{i}$ & & $* !$ & & $*$ & $*$ & \\
\hline c. ma lRab. $\int \mu$ & & & $* !$ & & & $*$ \\
\hline d. ma lRab.t $\mu . \int \mathrm{i}$ & & & & $*$ & $*$ & $*$ \\
\hline e. ma lR a.bit. $\int \mu$ & & & & & $*$ & $*$ \\
\hline f. ma 1?ab.tif & & & & & $*$ & \\
\hline
\end{tabular}

Table 2 further testifies the efficiency of the constraint hierarchy already established in (13) ${ }^{1}$ to optimize the optimal candidate from the input/ ma 1 ab-t- $\int$ ' II did not play'.

Candidate (a) is ruled out from the competition as it contains two adjacent semisyllables. Inserting /i/ after the morpheme $/ \int /$ does not secure $* 3 \mu$, ANCHORING-IO $(\mathrm{GrWd}, \mathrm{R})$ and DEP-IO and accordingly, oust candidate (b) from the competition. To abide by the two highly ranked constraints, candidate (c) deletes the morpheme /t/ which incurs a blatant cost of MAX-IO. Candidate (d) is also ruled out as it breaches ANCHORING-IO (GrWd,R), DEP-IO and

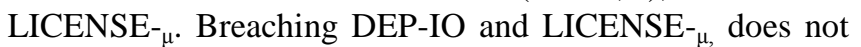
tolerate candidate (e) leaving candidate (f) as the only potential winner.

To sum up, the rationale behind /i/ insertion in word-final $\mathrm{C}(\mathrm{C})$ VCCCC and $\mathrm{C}(\mathrm{C}) \mathrm{VVCC}$ syllable structures in DJ crucially stems from the hegemony of the undominated constraints $* \varsigma \varsigma$ and $* 3 \mu$ that renders $/ \mathrm{i} /$ epenthesis imperative, being the least costly repair mechanism.

\section{2. /i/ Epenthesis to Break Word-Initial CCC Clusters}

DJ allows up to two Cs in word-initial position, as shown in the data in (14).

\begin{tabular}{|c|c|}
\hline ktibt & 'I wrote' \\
\hline fhamt & 'I understood' \\
\hline $\int$ rabt & 'I drank' \\
\hline
\end{tabular}

It is worthwhile to mention here that the word-initial CC clusters in the data above result from vowel syncope. In order to fully entertain Kiparsky's licence mora proposal in the analysis advanced in this paper, we assume that the word-initial stranded $C$ in the data in (14) is also a semisyllable directly affiliated to the prosodic word. DJ, however, does not allow word-initial tri-consonantal clusters. These CCC clusters crop up by means of morphological concatenation; namely the passive voice formation. In the investigated dialect, passive voice is concatenated by prefixing the morpheme $/ \mathrm{t} /$ to the verb stems. But when $/ \mathrm{t} /$ is

$1 \mathrm{Max}-\mu_{\mathrm{v}}$ is excluded from table 2 as it does not discriminate among the candidates. appended to stems starting with bi-consonantal clusters, it rather culminates in an ill-formed structure with three-consecutive Cs word-initially. Consider the data in (15).

(15)

\begin{tabular}{|c|c|c|c|}
\hline Input & Output & Output & Gloss \\
\hline t-ktib & *tktib & tiktib & 'it was written' \\
\hline t-rfaS & *trfaS & tirfas & 'it was lifted' \\
\hline t-fham & *tfham & tifham & 'it was understood' \\
\hline $\mathrm{t}-\int \mathrm{rab}$ & $* \mathrm{t} \int \mathrm{rab}$ & $\mathrm{ti} \int \mathrm{rab}$ & 'it was drunk' \\
\hline $\mathrm{t}$-sraq & $*$ tsraq & tisraq & 'it was stolen' \\
\hline
\end{tabular}

As clearly demonstrated in the data in (15), DJ bans three consecutive consonants word-initially. To capture the ban on these illicit clusters within OT, we may resort to the constraint *CCC that bans the succession of three Cs.

\section{(16) $* \mathrm{CCC}$}

Tri-consonantal CCC clusters are not allowed.

Since DJ allows CCC clusters word-medially, we may specify such a constraint to $* \mathrm{CCC}$ (word-initial) that can be reformulated in (17).

\section{(17) *CCC (word-initial)}

Word-initial tri-consonantal clusters are not allowed.

But in the spirit of the proposal adopted in this paper, we may assume that both of the first two Cs are semisyllables directly affiliated to the prosodic word and that the dialect's ban on the adjacency of two semisyllables is what motivates /i/ epenthesis.

In order to resolve the adjacency of two semisyllables in word-initial position, DJ, alternatively, could have dropped one of the two Cs. Yet, consonant syncopation does not pay off as it is prone to culminate in the wrong output and breaches MAX-IO that is ranked very high in the dialect. Since, MAX-IO outranks DEP-IO, DJ resorts to vowel epenthesis to break word-initial tri-consonantal clusters. Such epenthetic segment, however, can be either inserted between $\mathrm{C} 1$ and $\mathrm{C} 2$ as in $\mathrm{CvCC}$ or $\mathrm{C} 2$ and $\mathrm{C} 3$ as in $\mathrm{CCvC}$. In order to decide on the docking site of the epenthetic vowel, we make recourse to two contiguity constraints, namely, JUNCTURE CONTIGUITY and DOMAIN CONTIGUITY. 
Table 3. Constraint tableau: $/ \mathrm{t}-\mathrm{ktib} / \rightarrow[$ tiktib]

\begin{tabular}{|c|c|c|c|c|c|c|}
\hline $\begin{array}{c}\text { Input } \\
\text { /t-ktib/ }\end{array}$ & *\$S & MAX-IO & D-CONTIG & J-CONTIG & DEP-IO & LICENSE $_{-\mu}$ \\
\hline a. $t \mu . k \mu . t i b$ & $* !$ & & & & & $* *$ \\
\hline 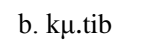 & & $* !$ & & & & $*$ \\
\hline c. tu.kitib & & & * & & * & $*$ \\
\hline d. tiktib & & & & * & $*$ & \\
\hline
\end{tabular}

\section{(18) JUNCTURE CONTIGUITY (J-CONTIG) [20]}

Contiguity between correspondents across identical domains: For two identical domains $\mathrm{D}$ and $\mathrm{D}+1$ in $\mathrm{S} 2$, where $\beta$ is the final correspondent in $D$ and $\alpha$ is the first correspondent in $\mathrm{D}+1$, and $\beta$ must be contiguous. Where $\mathrm{D}$ $=\{$ Syllable, Foot, PrWd, etc. $\}$

\section{(19) DOMAIN CONTIGUITY (D-CONTIG) [20]}

Contiguity between correspondents within a domain D: For some domain D within S2, all correspondents $\alpha \beta$ in D must be contiguous. Where D $=\{$ Syllable, Foot, PrWd, etc.

D-CONTIG implies that no insertion takes place within the stem domain, whereas, J-CONTIG bans any epenthesis between the morpheme and the stem. Optimizing /i/ epenthesis between $\mathrm{C} 1$ and $\mathrm{C} 2$ definitely points out that D-CONTIG is ranked higher than J-CONTIG in DJ grammar.

After figuring out all the constraints at play, the constraints permutation elucidating the optimization of $\mathrm{CvCC}$ over $\mathrm{CCvC}$ is adduced in (20).

\section{(20) $* \zeta \varsigma>>$ MAX-IO $>>$ D-CONTIG $>>$ J-CONTIG $>>D E$ P-IO >>LICENSE- $\mu$}

Table 3 further elucidates the optimization of [tiktib] 'it was written' over its competitors.

Affiliating the two stranded Cs to semisyllables violates the undominated $* \varsigma \zeta$ and incurs two marks of violations of LICENSE $_{-\mu}$ and accordingly, candidate (a) is discarded. Candidate (b) is also ruled out as it breaches MAX-IO and LICENSE- ${ }_{\mu}$. The suboptimal candidate (c) is excluded as it violates D-CONTIG, DEP-IO and LICENSE- $_{\mu}$ leaving candidate (d) as the only potential winner.

\section{Vowel Hiatus}

Like other Arabic varieties, DJ does not tolerate the adjacency of two heterosyllabic vowels, a common phonological phenomenon coined vowel hiatus. The latter mainly crops up by means of morphological concatenation in the examined variety. There are two main instances of vowel hiatus attested in the dialect: a vowel hiatus resulting from the concatenation of the feminine morpheme /a/ to nouns and adjectives ending in the high vocalic segments $/ \mathrm{i} /$ and $/ \mathrm{u} /$; and another instance resultant from the suffixation of the plural morpheme $/ \mathrm{u} /$ and the imperative second singular feminine morpheme /i/ to verbs ending in the low vowel /a/. Interestingly, the dialect utilizes two different strategies to rehabilitate such anomaly: glide epenthesis to resolve the hiatus resulting from the feminine morpheme concatenation and devocalization to repair the hiatus caused by the concatenation of the plural morpheme $/ \mathrm{u} /$ and the imperative second singular feminine morpheme /i/. Yet, such apparent opacity seems not to be well-accounted for within the OT enterprise advocated in this paper in the way that vowel hiatus cannot be once resolved by glide insertion and another time by devocalization. However, such opacity is only apparent since glide epenthesis is only inserted when the first member of the hiatus is a high segment and accordingly, glide insertion is blocked when the first segment of the hiatus is not. Let's first see how vowel hiatus is resolved by glide insertion in the dialect.

\subsection{Glide Epenthesis}

The declension of nouns and adjectives for feminine gender in DJ is achieved by suffixing the morpheme /a/ word-finally. But in case these nouns or adjectives end in the high vocalic segments $/ \mathrm{i} /$ and $/ \mathrm{u} /$, the suffixation of the morpheme /a/ culminates in vowel hiatus. Consider the data in (21).

(21)

\begin{tabular}{|c|c|c|c|}
\hline Input & Output & Output & Gloss \\
\hline mu:ha:mi:-a & *mu:ha:mi:a & mu:ha:mi:ja & 'lawyer' \\
\hline bu:li:si:-a & * bu:li:si:a & bu:li:si:ja & 'police woman' \\
\hline qa:ðSi:-a & *qa:ðSi:a & qa:ðSi:ja & 'judge' \\
\hline Sa:di:-a & * Sa:di:a & Sa:di:ja & 'normal' \\
\hline hlu:-a & *hlu:a & hlu:wa & 'sweet' \\
\hline
\end{tabular}

As revealed in the data above, the suffixation of the low vowel /a/ to nouns and adjectives ending in $/ \mathrm{i} /$ and $/ \mathrm{u} /$ results in an onsetless ultimate syllable /a/ which violates the highly ranked constraint ONS. Moreover, such affixation yields the prohibited succession of two heterosyllabic vocalic segments. To cast this maneuver in the light of OT, we make recourse to the markedness constraints NO HIATUS and ONS.

\section{(22) NO HIATUS [21]}

Two adjacent vowels are not allowed.

\section{(23) ONSET (ONS) [3]}

All syllables must have onsets.

Cross-linguistically, to avoid vowel hiatus, languages 
either opt for deleting one of the two vowels or inserting a [-syllabic] segment intervocalically. To satisfy ONS and NO HIATUS, DJ may either syncopate the stem-final vowel or the suffix /a/. But such deletion culminates in the wrong output such as the input /mu:ћa:mi:-a/ 'a lawyer. fem' that

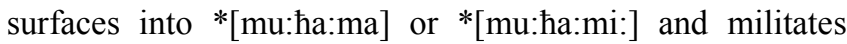
against the anti-deletion faithfulness constraint MAX-IO and hence, such strategy is no longer advocated. The least costly strategy the dialect opts for is inserting a [-vocalic] segment intervocalically. By means of invoking the relevant constraints, the following hierarchy is established.

\section{(24) ONS, NO HIATUS $>>$ MAX-IO $>>$ DEP-IO}

The interaction of these constraints to optimize the optimal output from the input /mu:ha:mi:-a/ 'a lawyer.fem' is tested in table 1:

Table 4. Constraint tableau: /mu:ћa:mi:-a/ $\rightarrow$ [mu:ha:mi:ja]

\begin{tabular}{|c|c|c|c|c|}
\hline $\begin{array}{c}\text { Input } \\
\text { /mu:ha:mi:-a/ }\end{array}$ & ONS & $\begin{array}{c}\text { NO } \\
\text { HIATUS }\end{array}$ & MAX-IO & DEP-IO \\
\hline a. mu:ha:mi:a & $* !$ & $* !$ & & \\
\hline b. mu:ha:ma & & & $* !$ & \\
\hline $\begin{array}{c}\text { (:) c. } \\
\text { mu:ћa:mi:?a }\end{array}$ & & & & $*$ \\
\hline $\begin{array}{c}\text { (:) d. } \\
\text { mu:ha:mi:ja }\end{array}$ & & & & $*$ \\
\hline
\end{tabular}

Constraints interaction in the tableau above definitely rules out candidate (a) as it fatally contravenes ONS and NO HIATUS that are ranked very high in the hierarchy. Being faithful to the two highly ranked constraints does not rescue candidate (b) as it fatally breaches MAX-IO by means of eliding the stem-final vowel. Yet, both candidates (d) and (c) incur the least violation of DEP-IO: the former by inserting a glide and the latter by inserting a glottal stop. To decide on the epenthetic segment being either a glide or a glottal stop, we refer to Huffman [22] proposal. The proposal he puts forward vis-à-vis the selection of the epenthetic segment bears on two counts: prosodic position and prominence contrast. Based on the latter, glottal stop epenthesis is induced to maximize the contrast to the following vowel while glide insertion is invoked to minimize the contrast to the following or preceding vowel [22]. Following Huffman [22], we argue that glottal stops are the most unmarked margin consonants and glides as the most unmarked peak consonants. To exclude intervocalic glottal stop epenthesis in DJ, we may refer to the markedness hierarchy in (25).

\section{(25) $* \mathrm{~V}$ V/lar $>>* V$ V/obs $>>* V$ V/nas $>* V V / l>>* V$ $\mathrm{V} / \mathrm{r}>>* \mathrm{~V} \mathrm{~V} / \mathrm{V}$ [22]}

As revealed from the markedness hierarchy above, intervocalic laryngeal segments are the most marked, while intervocalic glide insertion is the most unmarked. It follows from this that the dialect is in compliance with such hierarchy in the way that it opts for intervocalic glide insertion rather than glottal stop insertion. Consider the data in (26).

\section{(26)}

\begin{tabular}{|c|c|c|c|}
\hline Input & Output & Output & Gloss \\
\hline ra:Si:-a & ra:Si:ja & *ra:Si:? a & 'shepherd fem' \\
\hline bu:li:si:-a & bu:li:si:ja & *bu:li:si:?a & 'police woman' \\
\hline mu:ha:mi:-a & mu:h:ami:ja & *mu:ha:mi:?a & 'lawyer .fem' \\
\hline Sa:di:-a & Sa:di:ja & *Sa:di:?a & 'normal.fem' \\
\hline ћlu:-a & hlu:wa & *hlu:?a & 'sweet.fem' \\
\hline
\end{tabular}

DJ resolves vowel hiatus by means of intervocalic glide insertion either the bilabial glide / $\mathrm{w} /$ or $/ \mathrm{j} /$ which falls in harmony with the preceding vowels in terms of roundness and the back feature. This can be sketched out through the following rule:

$$
\emptyset \rightarrow\left[\begin{array}{c}
- \text { syll } \\
- \text { cons } \\
\alpha \text { back } \\
\alpha \text { round }
\end{array}\right] /\left[\begin{array}{c}
+ \text { high } \\
+ \text { syll } \\
\text { a back } \\
\alpha \text { round }
\end{array}\right]-\left[\begin{array}{c}
- \text { high } \\
+ \text { syll } \\
- \text { round }
\end{array}\right]
$$

It is worthwhile to capture the quality of the epenthetic glide by a constraint. In DJ $/ \mathrm{j} /$ is inserted when it is preceded by the high front vowel $/ \mathrm{i} /$, while the bilabial glide is inserted after the high back vowel /u/. It follows from this that we are in need for a context sensitive constraint that elucidates such harmony. To capture this harmony scenario by a constraint, we make recourse to the markedness constraint SHARE (F) [23] and propose the following ad hoc constraint:

\section{(28) SHARE (round, back)}

The inserted glide should be linked to the same token feature with the preceding vowel in terms of backness and roundness.

So far, the vowel hiatus resulting from the concatenation of the feminine morpheme $/ \mathrm{a} /$ to stems ending in $/ \mathrm{i} /$ and $/ \mathrm{u} /$ is resolved by intervocalic glide insertion. Integrating $* \mathrm{~V}$ $\mathrm{V} / \mathrm{lar}>{ }^{*} \mathrm{~V} \mathrm{~V} / \mathrm{V}$ and SHARE (round, back) in the hierarchy already established in (24) yields the dominance constraint hierarchy in (29).

\section{(29) ONS, NO HIATUS $>>$ MAX-IO $>>$ DEP-IO $>>* V$ V/lar $>* V$ V/V $>>S H A R E$ (round, back)}

Table 5 further demonstrates the optimization of

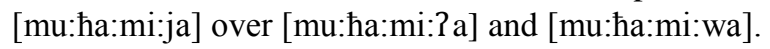


Table 5. Constraint tableau: /mu:ha:mi:-a/ $\rightarrow$ [mu:ha:mi:ja]

\begin{tabular}{|c|c|c|c|c|c|c|c|}
\hline $\begin{array}{c}\text { Input } \\
\text { /mu:ha:mi:-a/ }\end{array}$ & ONS & NO HIATUS & MAX-IO & DEP-IO & $\begin{array}{c}* \mathrm{~V} \\
\mathrm{~V} / \mathrm{Lar}\end{array}$ & $* \mathrm{~V} \mathrm{~V} / \mathrm{V}$ & $\begin{array}{l}\text { SHARE(round, } \\
\text { back) }\end{array}$ \\
\hline a. mu:ћa:mi:a & $* !$ & $* !$ & & & & & \\
\hline b. mu:ћa:ma & & & $* !$ & & & & \\
\hline c. mu:ћa:mi:?a & & & & $*$ & $*$ & & \\
\hline d. mu:ha:mi:wa & & & & $*$ & & $*$ & $*$ \\
\hline e. mu:ha:mi:ja & & & & $*$ & & $*$ & \\
\hline
\end{tabular}

DJ rescues vowel hiatus by intervocalic glide insertion which seems to be in compliance with the universal tendency to break such hiatus that is attested in many languages, viz., (Dutch, [24]; Korean, [25]; Czech, [26]; Sinhala, [27]; Japanese, [28]).

\subsection{Devocalization}

Another mechanism the dialect resorts to in order to resolve vowel hiatus is devocalization. Such hiatus again crops up via morphological concatenation. In this regard, when the third singular plural morpheme $/ \mathrm{u} /$ and the imperative second singular feminine morpheme /i/ are suffixed to verbs ending in the low vowel /a/, they culminate in vowel hiatus. Consider the data in (30).

\begin{tabular}{|c|c|c|c|}
\hline Input & Output & Output & Gloss \\
\hline bna:-u & *bna:u & bna:w & 'they built' \\
\hline 3ra:-u & ${ }^{*}$ 3ra:u & 3ra:w & 'they ran' \\
\hline thalla:-i & $*^{\text {thalla:i }}$ & thalla:j & 'take care.imp.fem.sg' \\
\hline
\end{tabular}

As it turns out from the data in (30), the suffixation of the high vowels /u/ and /i/ to stems ending in the low vowel /a/ culminates in ungrammatical outputs: Primarily, by breaching the highly ranked constraint ONS, as the ultimate syllables are onsetless; and by engendering vowel hiatus that is not tolerated in the dialect. To capture the prohibition of the adjacency of two syllabic segments within OT, we again refer to the markedness constraint NO HIATUS. Since DJ bans the adjacency of two vocalic segments, it makes use of one repair mechanism to resolve such anomaly. As revealed from the data in (30), DJ opts for devocalization rather than intervocalic glide insertion to rehabilitate the vowel hiatus. The dialect, however, could have elided one of the two adjacent vowels, but such elision militates against MAX-IO that is ranked higher in the grammar. Another solution the dialect could have opted for is intervocalic glide-insertion. Yet, glide-insertion is quite hopeless to rescue such vowel hiatus on two counts: first, it militates against the anti-insertion constraint DEP-IO and, hence, culminates in the wrong output as in /kla:u/ that surfaces into *[kla:wu]. Second, it goes against Uffmann [21] assumption that glides are inserted intervocalically only when the first vowel of the hiatus is [+high]. Since the first member of the hiatus is a low vowel, glide insertion is not well-motivated here. To capture it by a constraint, we may formulate the following ad hoc markedness constraint:

\section{(31) CONTIGUITY-IO ([-high]V)}

No medial epenthesis or deletion of segments when a [-high] vowel is followed by another vowel word-finally.

The least costly strategy DJ opts for to resolve the hiatus is to change the suffix vowels $/ \mathrm{u} /$ and $/ \mathrm{i} /$ into the bilabial glide $/ \mathrm{w} /$ and the palatal glide $/ \mathrm{j} / \mathrm{respectively.} \mathrm{Such} \mathrm{segment}$ change only targets the vocalic feature in the way that $/ \mathrm{u} /$ and /i/ share almost the same features with the glides /w/ and /j/ respectively except syllabicity. This implies that such segmental change violates the faithfulness constraint IDENT-IO that requires the congruency between input and output vowel in terms of vocalic feature.

\section{(32) IDENT-IO (vocalic)}

The vocalic feature of input vowels should be kept intact in the output.

Such version of IDENT-IO constraint is demoted in the dialect grammar hierarchy and accordingly, devocalization is deemed to be the last resort the dialect opts for. Having recalled all the relevant constrains, the following constraint dominance hierarchy is established and further illustrated in table 6 .

\section{(33) ONS, NO HIATUS >>MAX-IO >>DEP-IO, CONTIGUITY-IO ([-high]V)>>IDENT-IO} (vocalic)

Table 6. /bna:-u/ $\rightarrow[$ bna:w $]$

\begin{tabular}{|c|c|c|c|c|c|c|}
\hline Input /bna:-u/ & ONS & NO HIATUS & MAX-IO & DEP-IO & $\begin{array}{l}\text { CONT-IO } \\
\text { ([-high]V) }\end{array}$ & $\begin{array}{c}\text { IDENT-IO } \\
\text { (vocalic) }\end{array}$ \\
\hline a. bna:u & $* !$ & $* !$ & & & & \\
\hline b. bna: & & & $* !$ & & & \\
\hline c. bna:wu & & & & $*$ & $*$ & \\
\hline d. bna:w & & & & & & $*$ \\
\hline
\end{tabular}


Candidate (a) is radically discarded as it incurs two violations of the two top-most ranked constraints. Candidate (c) is also excluded on two counts, by breaching DEP-IO and CONTIGUITY-IO ([-high]V). The fatal violation of MAX-IO ousts candidate (b) from competition, leaving candidate (d) as the only potential optimal candidate as it incurs the minimal violation. It follows from this that DJ resolves the vowel hiatus by virtue of glide epenthesis unless the first member of the hiatus is a low segment and accordingly, devocalization is induced. Put it differently, devocalization rather than glide epenthesis is operative here due to the hegemony imposed by the markedness constraint CONTIGUITY-IO ([-high]V) that outranks IDENT-IO (vocalic).

\section{Conclusions}

This paper is an attempted scrutiny into some phonological processes in DJ, viz., epenthesis and devocalization. It sketches out how DJ resorts to these repair mechanisms to rehabilitate the undesired syllable structures mainly resultant from morphological concatenation. Drawing on the basic tenet of OT, the paper elucidates how the markedness and the faithfulness constraints conflict with each other to compel the optimal outputs attested in the dialect. The paper concludes that word-final $\mathrm{C}(\mathrm{C}) \mathrm{VVCC}$ and $\mathrm{C}(\mathrm{C})$ VCCC syllables and word-initial CCC clusters are banned on the grounds that two contiguous semisyllables are not tolerated in the dialect and accordingly, motivate /i/ epenthesis. Furthermore, it addresses the vowel hiatus resulting from morphological concatenation. As we have seen, such anomaly is rehabilitated via glide insertion unless the first member of the hiatus is a [-high] segment and, hence, devocalization is ensued.

\section{REFERENCES}

[1] Broselow, E. 1979.Cairene Arabic syllable structure. Linguistic Analysis 5: 345-382

[2] Broselow, E. 1992. Parametric Variation in Arabic dialect phonology. In Mushira Eid \& John J. McCarthy (eds.) Perspectives on Arabic linguistics IV. Amsterdam \&Philadelphia: John Benjamins. 7-47.

[3] Ito, J. 1986. Syllabe Theory in Prosodic Phonology. PhD. Dissertation, University of Massachusetts at Amhert.

[4] Abu-Mansour, M. 1987. A Nonlinear Analysis of Arabic Syllabic Phonology, with Special Reference to Makkan. Ph.D. dissertation, University of Florida, Gainesville, Florida.

[5] Abu-Mansour, M. 1991. Epenthesis in Makkan Arabic: Unsyllabified Consonants versus Degenerate Syllables. In Perspectives on Arabic Linguistics III: Papers from the third annual symposium on Arabic Linguistics, eds. Bernard Comrie and Mushira Eid, 137-154. Amsterdam: John Benjamins Publishing Company.

[6] Kiparsky, P. 2003. Syllables and moras in Arabic. The Syllable in Optimality Theory ed. by Caroline Féry and Ruben van de Vijver, 147-182. Cambridge:Cambridge
University Press.

[7] Gouskova, M. \& N. Hall. 2007. Levantine Arabic epenthesis: Phonetics, phonology and learning. Poster presented at the Workshop on Variation, Gradience and Frequency in Phonology. 6-8 July 2007, Stanford, CA: Stanford University.

[8] Watson, J. 2007. "Syllabification patterns in Arabic dialects: long segments and mora-sharing", Phonology, vol.24, 335-356,

[9] McCarthy, J. 2007. What is Optimality Theory, Linguistics Department Faculty Publishing Series 93, 1-29.

[10] Al-Mohanna, F. (1998) Syllabification and Metrification in Urban Hijazi Arabic: between rules and constraints. PhDthesis.University of Essex.

[11] Watson, J.C.E. 2002. The phonology and morphology of Arabic. Oxford: Oxford University Press.

[12] Kager, R. 1999. Optimality theory. New York: Cambridge University Press

[13] Hayes, B. (1995) Metrical Stress Theory: Principles and Case Studies. University of Chicago Press.

[14] Kager, R.1995b. Surface opacity of metrical structure in optimality theory. University of Utrecht, MS.

[15] Kenstowicz, M.J. 1994b.Phonology in Generative Grammar. Blackwell

[16] Hall, N. 2011. Vowel Epenhesis. In Marc van Oostendrop, Colin Ewen, Elizabeth Hume and Keren Rice, Companion to Phonology. Oxford: Wiley-Blackwell 1576-1596.

[17] Broselow, Ellen. 1982. On predicting the interaction of stress and epenthesis. Glossa 16.115-131.

[18] McCarthy, J.J. 1995. 'Extensions of faithfulness: Rotuman revisited', Rutgers Optimality Archive.

[19] McCarthy, J. \& Prince, A. 1995. Faithfulness and reduplicative identity. In Beckman, Walsh Dickey, and Urbanczyk, 249-384.

[20] Lamontagne, G. 1996. Relativized contiguity, Part I: Contiguity and syllabic prosody, Ms. University of British Columbia,Vancouver, Rutgers Optimality Archive - 150.

[21] McCarthy, John J. 2002. On targeted constraints and cluster simplification. Phonology19, 273-292.

[22] Uffmann, C. 2007. "Intrusive [r] and Optimal Epenthetic Consonants". Language Sciences 29, 451-476.

[23] McCarthy, J. 2011. Autosegmental spreading in Optimality Theory. Availale at: https://works.bepress.com/john_j_mccarthy/100/.

[24] Booij, G. 1995. The Phonology of Dutch. Clarendon, Oxford.

[25] Kang, O. 1999. A correspondence analysis on hiatus resolution in Korean. Ms. Chosun University [ROA 375].

[26] Rubach, J. 2000. Glide and glottal stop insertion in slavic languages: a DOT analysis. Linguistic Inquiry 31, 271-317.

[27] Smith, J.L. 2001. Lexical category and phonological contrast. In: Kirchner, R., Pater, J., Wikely, W. (Eds.), PETL 6: Proceedings of the Workshop on the Lexicon in Phonetics and Phonology. University of Alberta, Edmonton, pp. 61-72.

[28] Kawahara, S. 2002. Feature Recycling: Hiatus Resolution by Way of Glide Formation in Japanese. Talk presented at International Christian University, Tokyo. 